\title{
Origanum vulgare subsp. hirtum Essential Oil Prevented Biofilm Formation and Showed Antibacterial Activity against Planktonic and Sessile Bacterial Cells
}

\author{
DOMENICO SCHILLACI, ${ }^{1 *}$ EDOARDO MARCO NAPOLI, ${ }^{2}$ MARIA GRAZIA CUSIMANO, ${ }^{3}$ MARIA VITALE, ${ }^{3}$ \\ AND GIUSEPPE RUBERTO ${ }^{2}$
}

\begin{abstract}
${ }^{1}$ Dipartimento di Scienze e Tecnologie Biologiche, Chimiche e Farmaceutiche "STEBICEF," Università degli Studi di Palermo, Via Archirafi, 3290123 Palermo, Italy; ${ }^{2}$ Istituto del CNR di Chimica Biomolecolare, Via P. Gaifami, 1895126 Catania, Italy; and ${ }^{3}$ Istituto Zooprofilattico Sperimentale della Sicilia “A. Mirri,” Via G. Marinuzzi, 390129 Palermo, Italy
\end{abstract}

MS 13-001: Received 28 December 2012/Accepted 2 May 2013

\begin{abstract}
Essential oils from six different populations of Origanum vulgare subsp. hirtum were compared for their antibiofilm properties. The six essential oils (A to F) were characterized by a combination of gas chromatography with flame ionization detector and gas chromatography with mass spectrometer detector analyses. All oils showed weak activity against the planktonic form of a group of Staphylococcus aureus strains and against a Pseudomonas aeruginosa ATCC 15442 reference strain. The ability to inhibit biofilm formation was investigated at sub-MIC levels of 200, 100, and $50 \mu \mathrm{g} / \mathrm{ml}$ by staining sessile cells with safranin. Sample E showed the highest average effectiveness against all tested strains at $50 \mu \mathrm{g} / \mathrm{ml}$ and had inhibition percentages ranging from 30 to $52 \%$. In the screening that used preformed biofilm from the reference strain P. aeruginosa, essential oils A through $\mathrm{E}$ were inactive at $200 \mu \mathrm{g} / \mathrm{ml} ; \mathrm{F}$ was active with a percentage of inhibition equal to $53.2 \%$. Oregano essential oil can inhibit the formation of biofilms of various food pathogens and food spoilage organisms.
\end{abstract}

Pathogens growing as biofilms are highly resistant to conventional antimicrobials, and there is an urgent need to find novel antibiofilm agents, treatments, and therapies (15). Staphylococcus aureus and Pseudomonas aeruginosa are well-known biofilm-forming microorganisms that cause chronic infections and biomaterial- and device-associated infections related to human and animal health (13). Therefore, the impact of these very common bacterial communities on food safety, food-transmitted diseases, and food spoilage must be reconsidered (25). A recent study focused on sessile growth as a biofilm in $S$. aureus and the production of enterotoxins in food environments (24). $P$. aeruginosa, well known for its capability to form strong and mature biofilms, is ubiquitous in all wet surfaces. All animal and plant tissues, and inert surfaces, can be colonized by $P$. aeruginosa biofilm (8). P. aeruginosa biofilm is a severe complicating factor in bovine mastitis, which is often associated with contaminated udder washing water or contaminated intramammary dry-cow preparations (19). Moreover, biofilms of Staphylococcus and Pseudomonas are common causes of food spoilage (14).

A screen-based method is commonly used to find novel antimicrobials that may offer an alternative to conventional antibiotics; novel compounds (synthetic or natural) are

\footnotetext{
* Author for correspondence. Tel: + 3909123891914; Fax: + 390916236150; E-mail: domenico.schillaci@unipa.it.
}

screened for inhibiting bacterial biofilms through direct effects on bacterial growth and viability. The extracts and essential oils obtained from various plant species could be a source of new antimicrobial and anti-biofilm agents, due to their recognized antimicrobial activity (20).

Essential oils are volatile, natural, complex mixtures of several compounds characterized by a strong odor; they are produced by aromatic plants as secondary metabolites. Commonly, essential oils are obtained by a physical process involving steam, hydro-, or dry distillation, with the sole exception of citrus essential oils, which are mechanically obtained by peel expression (23). Currently, more than 3,000 essential oils are known, but only 300 of these are commercially traded for the pharmaceutical, agronomic, food, sanitary, cosmetic, and perfume industries (3). Of these, the essential oil of oregano is one of the more interesting due to its wide distribution and its worldwide use $(17,26)$. Oregano plant parts and biochemical extracts (herb, leaf, essential oil, etc.) are commonly used as spices in the food industry and are well known for their pharmacological properties, including as antimicrobials $(12,22)$ and antioxidants $(11,18)$. The antimicrobial activity of oregano essential oils, known since antiquity, is probably due to its high content of phenolic derivatives, such as carvacrol and thymol (5). Due to their hydrophobicity, many components of oregano oil disrupt cell membranes, leading to bacterial cell death (27). 
Plant-derived essential oils have been tested for their ability to eliminate biofilms of Listeria monocytogenes on polystyrene and stainless steel surfaces. Preliminary screening of nine essential oils and related phenolic compounds revealed that thyme and oregano oils had the highest antimicrobial activity (9). This study evaluated the antibiofilm properties of some of the essential oils from six Sicilian populations of Origanum vulgare subsp. hirtum against strains of $S$. aureus and $P$. aeruginosa. In particular, the focus was on the ability of the tested samples to prevent bacterial biofilm growth rather than on the eradication of already formed biofilms.

\section{MATERIALS AND METHODS}

Essential oil collection. Air-dried aerial parts (leaves and inflorescences) of each plant (50 to $100 \mathrm{~g}$ ) were subjected to hydrodistillation in accordance with current European Pharmacopoeia standards (10) until there was no significant increase in the volume of oil collected $(3 \mathrm{~h})$. The oils were dried using anhydrous sodium sulphate and were stored under $\mathrm{N}_{2}$ in a sealed vial until use.

GC-FID and GC-MS analyses. The essential oils were characterized by a combination of gas chromatography with flame ionization detector (GC-FID) and gas chromatography with mass spectrometer detector (GC-MS) analyses. A Shimadzu GC-17A gas chromatograph (Kyoto, Japan) equipped with a fused silica capillary column ( $15 \mathrm{~m}$ by $0.1 \mathrm{~mm}$ by $0.1 \mu \mathrm{m}$; SPB-5, Supelco, Bellefonte, PA) and FID was used, under the following operating conditions: $60^{\circ} \mathrm{C}$ for $1 \mathrm{~min}, 60$ to $280^{\circ} \mathrm{C}$ at $10^{\circ} \mathrm{C} / \mathrm{min}$ and then $280^{\circ} \mathrm{C}$ for $1 \mathrm{~min}$; injector temperature $250^{\circ} \mathrm{C}$; detector temperature $280^{\circ} \mathrm{C}$; carrier gas helium (1 ml/min); split mode (1:200). Percentages of compounds were determined from their peak areas in the GC-FID profiles. GC-MS analyses were performed on a Shimadzu GCMS-QP5050A, using the same column and the same operating conditions as were used for GC-FID. Ionization was performed at $70 \mathrm{eV}$, and ion source temperature was $180^{\circ} \mathrm{C}$. Mass spectral data were acquired in the scan mode in $\mathrm{m} / \mathrm{z}$ range 40 to 400. Oil solutions were injected with the split mode of 1:96.

Identification procedure. The identity of components was based on their retention index relative to $\mathrm{C}_{9}$ to $\mathrm{C}_{22} n$-alkanes standard mixture on the SPB-5 column, computer matching of mass spectra data from National Institute of Standards and Technology (NIST) MS 107 and NIST 21 libraries, comparison of the fragmentation patterns with those reported in the literature (1), and whenever possible, coinjections with authentic samples. Pure standards were purchased from Sigma-Aldrich Co. (Milan), Alltech Italia (Milan), and Extrasynthese (Lyon, France).

Bacterial strains. The staphylococcal reference strains used were S. aureus ATCC 29213, known for its ability to form a biofilm, and S. aureus ATCC 6538, used as a reference strain for antibacterial evaluation of basic bactericidal activity in vitro (Ente Nazionale Italiano Unificazione [UNI EN] European Standard). Two staphylococcal isolates from the Istituto Zooprofilattico Sperimentale, Sicily, Italy, bacterial collection, including S. aureus 353 (from sheep's milk) and S. aureus 708 (from fresh cheese), were also used. The isolates were selected on blood agar plates and on mannitol salt agar (Difco, BD, Sparks, MD). The colonies were typed by API Staph strip (bioMérieux S.A., Marcy l'Etoile, France), and a tube coagulase test was performed (4). $P$. aeruginosa ATCC 15442, the reference strain in official tests for antibacterial evaluation in vitro (UNI EN European Standard), was also used in this study.

Determination of MICs. MICs against planktonic strains were determined by an agar dilution method using tryptic soy agar (Sigma-Aldrich). Briefly, a suitable volume of a solution of essential oils in dimethyl sulfoxide (Sigma-Aldrich) was added to $20 \mathrm{ml}$ of molten medium at $50^{\circ} \mathrm{C}$ to obtain the required concentrations (1,000 to $50 \mu \mathrm{g} / \mathrm{ml})$, and the resulting mixture was poured onto plates and allowed to solidify. The plates were inoculated with bacterial suspensions from a 24-h culture containing $\sim 10^{6} \mathrm{CFU} / \mathrm{ml}$ of each tested strain. The plates were incubated at $37^{\circ} \mathrm{C}$, and the MIC was considered to be the lowest concentration of the sample yielding no visible growth (6).

Evaluation of biofilm formation. All the bacterial strains were tested for their ability to form biofilms. Briefly, bacteria were grown overnight at $37^{\circ} \mathrm{C}$ in a shaking bath in tryptic soy broth (TSB; Sigma-Aldrich) containing $2 \%$ glucose and then were diluted 1:200 to a suspension with optical density (OD) at $570 \mathrm{~nm}$ of about 0.040 , corresponding to $\sim 10^{6} \mathrm{CFU} / \mathrm{ml}$. Next, 24-well polystyrene tissue culture plates were filled with $1 \mathrm{ml}$ of diluted suspension and incubated for $24 \mathrm{~h}$ at $37^{\circ} \mathrm{C}$. Then the wells were washed three times with $1 \mathrm{ml}$ of sterile phosphate-buffered saline (PBS) and stained with $1 \mathrm{ml}$ of safranin $(0.1 \%, \mathrm{vol} / \mathrm{vol})$ for $1 \mathrm{~min}$. The excess stain was removed by placing the plates under running tap water. Plates were inverted and dried at $37^{\circ} \mathrm{C}$. Safranin-stained adherent bacteria in each well were redissolved to homogeneity in $1 \mathrm{ml}$ of $30 \%$ (vol/vol) glacial acetic acid, and the $\mathrm{OD}_{492}$ was read. Each assay was performed in triplicate and repeated at least twice.

Biofilm prevention assay. The procedure described above was used to evaluate the activity of the tested essential oils in preventing biofilm formation. Twenty-four-well polystyrene tissue culture plates were filled with $1 \mathrm{ml}$ of the above-mentioned diluted bacterial suspension $\left(\mathrm{OD}_{570}\right.$ of about 0.040$)$. At time zero, subMIC levels $(200,100,50 \mu \mathrm{g} / \mathrm{ml})$ of essential oils were directly added to the bacterial suspension, and plates were incubated at $37^{\circ} \mathrm{C}$ for $24 \mathrm{~h}$. After incubation, wells were washed and stained with safranin as before. By comparing the average OD of the growth in control wells (no oil added) with that in the sample wells, the following formula was used to calculate the percentages of inhibition for each concentration of the sample: [(OD growth control - OD sample)/OD growth control] $\times 100$. Each assay was performed in triplicate, and assays were repeated at least twice.

Antibiofilm activity. $P$. aeruginosa ATCC 1544 was grown overnight at $37^{\circ} \mathrm{C}$ in a shaking bath in TSB (Sigma-Aldrich) containing $2 \%$ glucose and diluted as described above. Diluted suspension $(1 \mathrm{ml})$ was added to 24 -well polystyrene tissue culture plates and incubated for $72 \mathrm{~h}$ at $37^{\circ} \mathrm{C}$. Then wells were washed three times with $1 \mathrm{ml}$ of sterile PBS and filled with $1 \mathrm{ml}$ of TSB medium containing a screening concentration of $200 \mu \mathrm{g} / \mathrm{ml}$ of each extract, or with $\gamma$-terpinene or thymol (pure standards purchased from Aldrich [97\% purity] and Sigma [99.5\% purity], respectively), or with a combination of the two, at various concentrations (48, $70,125 \mu \mathrm{g} / \mathrm{ml}$ ), and incubated at $37^{\circ} \mathrm{C}$ for $24 \mathrm{~h}$. After incubation, the medium was removed and adherent bacteria were stained with safranin as described above. ODs were read, and inhibition percentages were calculated as described above.

Statistical analysis. Biological data were subjected to a twoway analysis of variance (bacterial strain and essential oils concentrations), and when appropriate, means were compared by 
TABLE 1. Chemical composition of wild Sicilian oregano essential oils ${ }^{a}$

\begin{tabular}{|c|c|c|c|c|c|c|c|c|}
\hline No. & KI & Class/components & A & $\mathrm{B}$ & $\mathrm{C}$ & $\mathrm{D}$ & $\mathrm{E}$ & $\mathrm{F}$ \\
\hline & & Monoterpene hydrocarbons & 15.7 & 27.8 & 31.3 & 34.4 & 33.5 & 64.1 \\
\hline 4 & 931 & $\alpha$-Thujene & 0.6 & 1.5 & 1.7 & 2.0 & 1.7 & 3.2 \\
\hline 5 & 938 & $\alpha$-Pinene & 0.4 & 0.6 & 0.7 & 0.8 & 0.7 & 1.3 \\
\hline 6 & 954 & Camphene & $\mathrm{T}$ & 0.1 & 0.1 & 0.1 & 0.1 & 0.1 \\
\hline 7 & 976 & Sabinene & $\mathrm{T}$ & 0.2 & 0.1 & 0.1 & 0.1 & 0.2 \\
\hline 8 & 980 & $\beta$-Pinene & $\mathrm{T}$ & 0.5 & 0.4 & 0.5 & 0.1 & $\mathrm{~T}$ \\
\hline 11 & 991 & Myrcene & 1.0 & 2.1 & 2.2 & 2.5 & 2.3 & 4.2 \\
\hline 12 & 1005 & $\alpha$-Phellandrene & 0.1 & 0.3 & 0.3 & 0.3 & 0.4 & 0.6 \\
\hline 13 & 1012 & $p$-Menth-1-(7),8-diene & - & 0.1 & 0.1 & 0.1 & 0.1 & 0.1 \\
\hline 14 & 1018 & $\alpha$-Terpinene & 1.3 & 2.6 & 2.3 & 2.4 & 3.5 & 6.1 \\
\hline 15 & 1026 & p-Cymene & 4.4 & 4.7 & 6.3 & 12.0 & 4.4 & 9.4 \\
\hline 16 & 1030 & Limonene & 0.3 & 0.5 & 0.5 & 0.6 & 0.6 & 0.6 \\
\hline 17 & 1038 & cis- $\beta$-Ocimene & 0.5 & 0.9 & 2.0 & 0.7 & 0.4 & 2.8 \\
\hline 18 & 1049 & trans- $\beta$-Ocimene & 0.2 & 0.2 & 0.4 & 0.2 & 0.3 & 0.5 \\
\hline 19 & 1062 & $\gamma$-Terpinene & 6.4 & 13.4 & 14.1 & 12.0 & 18.6 & 34.8 \\
\hline \multirow[t]{2}{*}{21} & 1086 & Terpinolene & 0.5 & 0.1 & 0.1 & 0.1 & 0.2 & 0.2 \\
\hline & & Oxygenated monoterpenes & 81.4 & 69.7 & 65.9 & 62.4 & 63.7 & 31.0 \\
\hline 20 & 1068 & cis-Sabinene hydrate & 0.2 & 0.4 & 0.2 & 0.3 & 0.4 & - \\
\hline 22 & 1095 & Linalool & 0.5 & 0.3 & 0.3 & 0.6 & 0.9 & 0.4 \\
\hline 23 & 1164 & Borneol & 0.2 & 0.1 & 0.1 & 0.1 & 0.1 & 0.1 \\
\hline 24 & 1173 & Terpinen-4-ol & 0.8 & 0.5 & 0.5 & 0.7 & 0.6 & 0.8 \\
\hline 25 & 1188 & $\alpha$-Terpineol & 0.1 & $\mathrm{~T}$ & - & - & 0.1 & - \\
\hline 26 & 1220 & cis-Dihydrocarvone & - & - & 0.1 & - & - & - \\
\hline 27 & 1228 & Thymol methyl ether & 1.1 & 1.5 & 1.6 & 2.9 & 0.9 & 1.8 \\
\hline 28 & 1238 & Carvacrol methyl ether & 1.5 & 3.1 & 2.7 & 3.7 & 2.7 & 3.2 \\
\hline 29 & 1293 & Thymol & 61.9 & 49.0 & 49.2 & 52.9 & 57.1 & 24.5 \\
\hline 30 & 1296 & Carvacrol & 15.1 & 14.5 & 11.1 & 1.2 & 0.8 & 0.1 \\
\hline \multirow[t]{2}{*}{31} & 1342 & Thymol acetate & $\mathrm{T}$ & 0.3 & 0.1 & - & 0.1 & 0.1 \\
\hline & & Sesquiterpenes & 2.8 & 2.5 & 2.8 & 3.2 & 2.9 & 4.0 \\
\hline 32 & 1380 & $\beta$-Cubebene & 0.1 & - & - & - & - & - \\
\hline 33 & 1381 & $\alpha$-Copaene & - & - & 0.1 & 0.1 & - & - \\
\hline 34 & 1393 & $\beta$-Bourbonene & - & 0.1 & 0.1 & - & $\mathrm{T}$ & - \\
\hline 35 & 1408 & $\beta$-Caryophyllene & 0.6 & 0.6 & 0.9 & 0.8 & 1.0 & 1.2 \\
\hline 36 & 1442 & $\alpha$-Humulene & 0.1 & 0.1 & 0.1 & 0.2 & 0.1 & - \\
\hline 37 & 1449 & allo-Aromandrene & - & 0.1 & - & - & - & 0.1 \\
\hline 38 & 1463 & $\gamma$-Muurolene & 0.2 & 0.1 & 0.1 & 0.3 & 0.1 & 0.1 \\
\hline 39 & 1469 & Germacrene D & 0.1 & 0.3 & 0.3 & 1.0 & 0.5 & 1.2 \\
\hline 40 & 1498 & $\beta$-Bisabolene & 0.9 & 0.7 & 0.6 & 0.4 & 0.8 & 1.1 \\
\hline 41 & 1501 & $\alpha$-Muurolene & 0.1 & - & - & - & - & - \\
\hline 42 & 1502 & Biciclogermacrene & - & 0.1 & 0.1 & 0.2 & $\mathrm{~T}$ & - \\
\hline 43 & 1503 & $\gamma$-Cadinene & 0.2 & 0.1 & 0.1 & $\mathrm{~T}$ & 0.1 & 0.1 \\
\hline 44 & 1507 & $\delta$-Cadinene & 0.3 & 0.2 & 0.2 & $\mathrm{~T}$ & 0.3 & 0.2 \\
\hline 45 & 1561 & Spathulenol & - & - & 0.1 & 0.1 & - & - \\
\hline 46 & 1567 & Caryophillene oxide & 0.2 & - & 0.1 & 0.1 & - & - \\
\hline 47 & 1640 & $\alpha$-Cadinol & - & 0.1 & $\mathrm{~T}$ & - & $\mathrm{T}$ & - \\
\hline \multirow[t]{2}{*}{48} & 1646 & $\alpha$-Muurolol & - & $\mathrm{T}$ & - & - & - & - \\
\hline & & Others & 0.3 & 0.3 & 0.3 & 0.3 & 0.3 & 0.4 \\
\hline 1 & 777 & Butanoic acid methyl ester & - & 0.1 & - & - & - & 0.1 \\
\hline 2 & 778 & Butanoic acid & - & - & 0.1 & 0.1 & 0.1 & - \\
\hline 3 & 857 & 2-trans-Hexenal & - & 0.1 & 0.1 & - & - & - \\
\hline 9 & 981 & 1-Octen-3-ol & $\mathrm{T}$ & $\mathrm{T}$ & - & - & 0.1 & 0.3 \\
\hline 10 & 988 & 3-Octanone & 0.3 & 0.1 & 0.1 & 0.2 & 0.1 & - \\
\hline
\end{tabular}

${ }^{a}$ Numbers refer to elution order, and values (relative peak area percent) represent averages of three determinations. T, trace $(<0.05)$; KI, Kovats retention index relative to standard mixture of $n$-alkanes on SPB-5 column. 
Tukey's test at $5 \%$ significance of probability, using CoStat ver. 6.003 (CoHort Software, Monterey, CA).

\section{RESULTS AND DISCUSSION}

Chemical composition. Table 1 lists the composition of the essential oils of the six collected samples. In total, 48 components were fully identified, accounting for more than 98\% of the total composition. For an easier comparison of the oils, the components were grouped in four classes: monoterpene hydrocarbons, oxygenated monoterpenes, sesquiterpenes, and others. Monoterpenes, both hydrocarbons and oxygenated, were the most highly represented classes (95 to $97 \%$ of all oils). Monoterpene hydrocarbons accounted for between 15 and $64 \%$, oxygenated monoterpenes from 31 to $81 \%$. Note that the relative concentrations of the components are complementary for biosynthetic reasons. The sesquiterpenes and other classes were the least represented in all cases.

As seen in Table 1, sample A contains the highest amount of oxygenated monoterpenes (81.4\%) and the lowest amount of monoterpene hydrocarbons (15.7\%); whereas sample $\mathrm{F}$ shows the lowest content of oxygenated monoterpene $(31.0 \%)$ and the highest of monoterpene hydrocarbons $(64.1 \%)$. The profiles of $\mathrm{B}, \mathrm{C}, \mathrm{D}$, and $\mathrm{E}$ are intermediate between these: monoterpene hydrocarbon content ranges from 27.8 to $33.5 \%$ and oxygenated monoterpene content from 63.7 to $69.7 \%$.

Thymol is the main component of samples A to E; the main compound of sample $F$ is $\gamma$-terpinene. Other significant components present in all oils are p-cymene, $\alpha$ terpinene, myrcene, and $\alpha$-thujene (monoterpene hydrocarbons) and the methyl ether derivatives of thymol and carvacrol (oxygenated monoterpenes). Carvacrol is one the main components of samples A, B, and C (11.1 to $15.1 \%$ ), whereas it is present in negligible amounts in the other three samples. $\beta$-caryophyllene, $\beta$-bisabolene and, partially, germacrene-D are the main sesquiterpenes found, as is usual for this species. Chemical compositions of all samples are in accordance with chemotaxonomic studies already reported in the literature (21) for wild Sicilian oregano.

Activity against planktonic cells. The six essential oils were evaluated for their antimicrobial activity against planktonic forms of staphylococcal strains (reference and isolates) and against $P$. aeruginosa ATCC 15442. At $1,000 \mu \mathrm{g} / \mathrm{ml}$, essential oil $\mathrm{F}$ was not effective against any isolates. The other five oils had weak activity against staphylococcal strains, with MICs ranging between 1,000 and $800 \mu \mathrm{g} / \mathrm{ml}$. No antimicrobial activity was present against $P$. aeruginosa ATCC 15442, even at the maximum concentration tested $(1,000 \mu \mathrm{g} / \mathrm{ml})$ (Table 2$)$.

Activity against biofilm formation. The best strategy against microbial biofilms is to prevent their formation rather than to try to eliminate them after they form. With this objective, the ability of the oregano essential oils to inhibit biofilm formation of tested strains was evaluated in vitro at sub-MIC levels $(200,100$, and $50 \mu \mathrm{g} / \mathrm{ml})$. All six essential oils reduce biofilm formation of tested strains at the three concentrations previously tested (Fig. 1). At $200 \mu \mathrm{g} / \mathrm{ml}$, inhibition ranged from 32.6 to $77.8 \%$. The highest inhibition percentage was registered for $P$. aeruginosa ATCC 15442, against which almost all oils showed the maximum efficacy. The reference strains of $S$. aureus were highly inhibited, S. aureus ATCC 29213 more so than $S$. aureus ATCC 6538. The food isolates S. aureus 708 and 353 were less susceptible (Fig. 1). We do not know the reason for this. In all cases, the percentage of biofilm inhibition was proportional to the dose of essential oil used in the assay. Analyzing the behavior of essential oils against all strains and combining the results at the three concentrations $(200,100$, and $50 \mu \mathrm{g} / \mathrm{ml})$, it is possible to rank the effectiveness of oils in the following order: $\mathrm{E}>\mathrm{C}>\mathrm{B}>\mathrm{A}$ $>\mathrm{D}>\mathrm{F}$. Looking only at the lowest concentration, $50 \mu \mathrm{g} /$ $\mathrm{ml}$, for which inhibition values range from 16.0 to $59.8 \%$, the effectiveness order is slightly different: $\mathrm{E}>\mathrm{C}>\mathrm{D}>\mathrm{A}$ $>\mathrm{B}>\mathrm{F}$. However, both rankings indicate that oil $\mathrm{E}$ is the most efficacious and that $\mathrm{F}$ shows the weakest biological activity (Fig. 1).

For $P$. aeruginosa, the sole gram-negative strain tested in this study, inhibition ranged from 40.0 to $59.8 \%$; the most active oil was sample $\mathrm{D}$, and the least active was sample F (Fig. 1).

In the attempt to correlate the observed inhibition values with the compositional data of the oils, it seems that the oils with an "optimal" balance between the percentages of the two monoterpene classes (hydrocarbons and oxygenated) are more efficacious than those with an excess of one of the two classes (Fig. 2). Several components with a wellestablished antimicrobial activity belong to the monoterpene classes $(3,7)$. Finally, because of the high complexity of the chemical composition of the essential oils, there may be interactive and synergistic effects among the different components that result in the observed biological activity.

TABLE 2. Antimicrobial activity of the essential oils expressed as $M^{a} C^{a}$

\begin{tabular}{|c|c|c|c|c|c|}
\hline Oil & $\begin{array}{c}\text { S. aureus } \\
\text { ATCC } 29213\end{array}$ & S. aureus ATCC 6538 & S. aureus 708 & S. aureus 353 & $\begin{array}{l}\text { P. aeruginosa } \\
\text { ATCC } 15442\end{array}$ \\
\hline $\mathrm{A}$ & 1,000 & $>1,000$ & 800 & 800 & $>1,000$ \\
\hline $\mathrm{B}$ & 800 & $>1,000$ & 800 & 800 & $>1,000$ \\
\hline $\mathrm{C}$ & 1,000 & $>1,000$ & 800 & 800 & $>1,000$ \\
\hline $\mathrm{D}$ & 800 & $>1,000$ & 800 & 800 & $>1,000$ \\
\hline $\mathrm{E}$ & $>1,000$ & $>1,000$ & 800 & 800 & $>1,000$ \\
\hline $\mathrm{F}$ & $>1,000$ & $>1,000$ & $>1,000$ & $>1,000$ & $>1,000$ \\
\hline
\end{tabular}

${ }^{a}$ Values are expressed in micrograms per milliliter. 


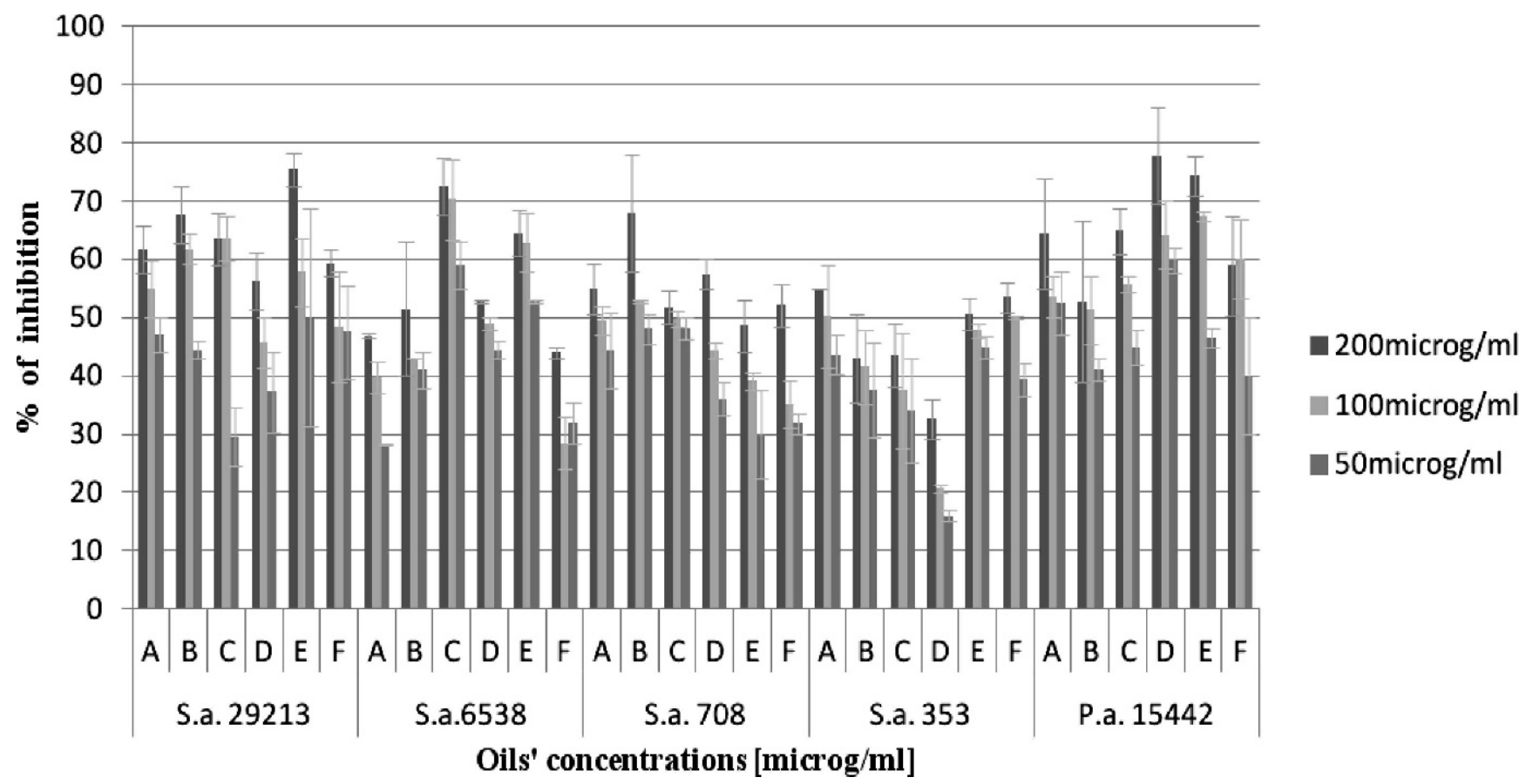

FIGURE 1. Inhibition of biofilm formation expressed as percentage of inhibition. Data are reported as means \pm standard deviations; $\mathrm{P}<0.05$. S.a., Staphylococcus aureus; P.a., Pseudomonas aeruginosa.

Antibiofilm effect. $P$. aeruginosa biofilm is a therapeutic challenge, and it causes recurrent and chronic infection in clinical and veterinary medicine. Moreover, its environmental persistence is a possible hazard in the food industry, and it is considered a major food spoilage microorganism. Data on the activity of oregano essential oils against biofilm formation prompted a test against a 72-h-old preformed biofilm of $P$. aeruginosa for evaluation of the antibiofilm effect. Essential oils were screened at $200 \mu \mathrm{g} / \mathrm{ml}$ but were not effective, with the exception of sample $F$, which showed an inhibition of $53.2 \%$. The difference may be due to the chemical composition of oregano essential oils. All samples, except sample F, were characterized by a high content of oxygenated monoterpenes $(63$ to $81 \%)$ and were particularly rich in thymol (48.9 to 61.9\%). In contrast, the major component of $\mathrm{F}$ was $\gamma$-terpinene (34.8\%), and thymol was present at $24.5 \%$.

To better understand the potential roles of thymol and $\gamma$ terpinene in the observed activity of $200 \mu \mathrm{g} / \mathrm{ml}$ of sample F, 48 and $70 \mu \mathrm{g} / \mathrm{ml}$ of each compound and a combination of the two were tested against a 72-h preformed $P$. aeruginosa biofilm. Thymol alone was also tested at $125 \mu \mathrm{g} / \mathrm{ml}$, which is the concentration found in $200 \mu \mathrm{g} / \mathrm{ml}$ of sample A (the essential oil richest in thymol content). The purified compounds, individually or in combination, were ineffective against the preformed biofilm. Only the intact oil, with its complex composition, had biological activity, suggesting that the interactive effect was the primary influence on inhibition.

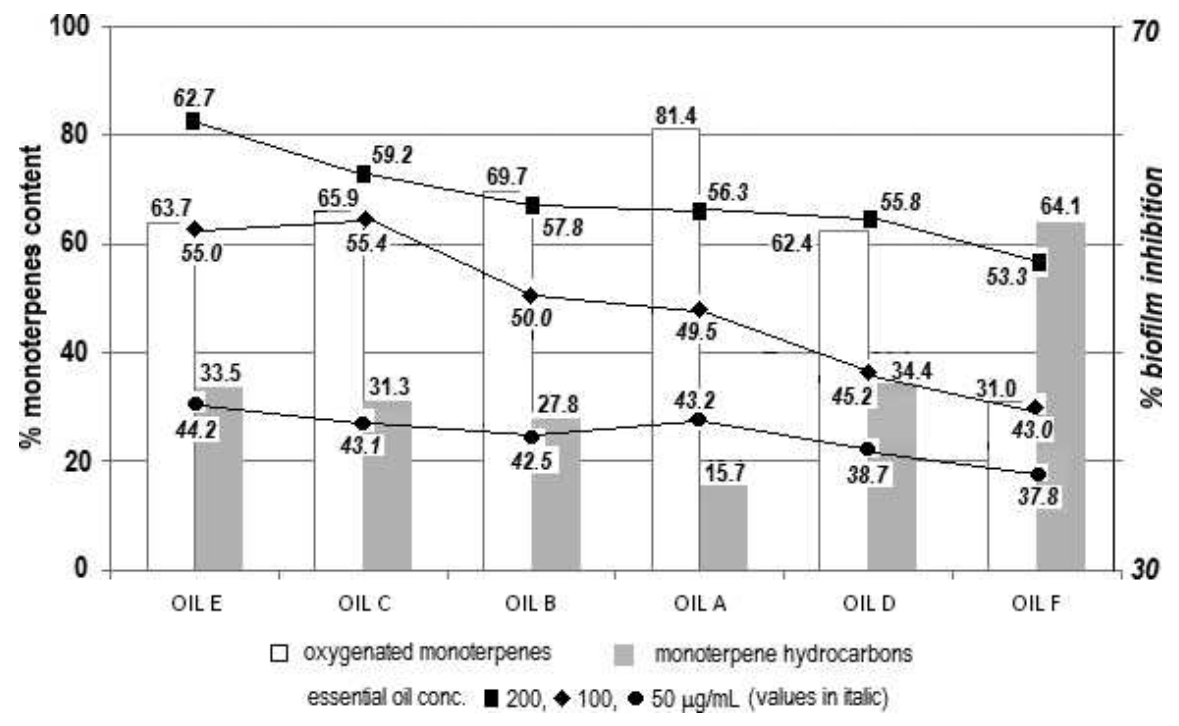

FIGURE 2. Monoterpene classes percentages correlated to biofilm inhibition. 
In any case, the activity of the essential oil is not directed against the planktonic form of $P$. aeruginosa (Table 2) but against biofilm formation and, at least in one case (sample F), against preformed biofilm. It is possible that essential oils interfere with intercellular communications in bacterial quorum sensing. Studies of anti-quorum sensing of essential oils have been reported in the literature $(2,16)$. A further and more detailed investigation on oregano essential oils anti-quorum sensing against $P$. aeruginosa is needed to confirm this hypothesis.

In conclusion, this study demonstrated that the analyzed samples are active in preventing biofilm formation of significant pathogens involved in human and animal diseases. Furthermore, the antiadhesion property of the tested essential oils could be very important against foodborne pathogens and biofilms of various organisms involved in food spoilage. Further studies are needed to better correlate the observed activity of oregano samples with their components to evaluate anti-quorum sensing and antibiofilm properties of the essential oils against other important food pathogens. Nevertheless, we believe that the essential oils of Sicilian oregano could potentially be used in formulations, in combination with other active principles, to prevent or eradicate microbial biofilms in the food industry.

\section{ACKNOWLEDGMENTS}

This work was supported by a grant from Università degli Studi di Palermo (Fondi di Ateneo, 2007) and by Consiglio Nazionale delle Ricerche (CNR-Rome). Acknowledgments are also due to Dr. Giovanni Avola (ISAFOM-CNR Catania) for helpful assistance in statistical data evaluation.

\section{REFERENCES}

1. Adams, R. P. 2001. Identification of essential oil components by gas chromatographic/quadrupole mass spectrometry. Allured Publishing Corporation, Carol Stream, IL.

2. Agnes-Szabo, M., G. Zoltan Varga, J. Homann, S. Schelz, E. Szegedi, L. Amaral, and J. Molnar. 2012. Inhibition of quorumsensing signals by essential oils. Phytother. Res. 24:782-786.

3. Bakkali, F., S. Averbeck, D. Averbeck, and M. Idaomar. 2008. Biological effects of essential oils. Food Chem. Toxicol. 46:446-475.

4. Berke, A., and R. C. Tilton. 1986. Evaluation of rapid coagulase methods for the identification of Staphylococcus aureus. J. Clin. Microbiol. 23:916-919.

5. Castilho, P. C., S. Savluchinske-Feio, T. S. Weinhold, and S. C. Gouveia. 2012. Evaluation of the antimicrobial and antioxidant activities of essential oils, extracts and their main components from oregano from Madeira Island, Portugal. Food Control 23:552-558.

6. Clinical and Laboratory Standards Institute. 2006. M7-A7. Methods for dilution antimicrobial susceptibility tests for bacteria that grow aerobically; approved standard, 7th ed. Clinical and Laboratory Standards Institute, Wayne, PA.

7. Cristani, M., M. D’Arrigo, G. Mandalari, F. Castelli, M. G. Sarpietro, D. Micieli, V. Venuti, G. Bisignano, A. Saija, and D. Trombetta. 2007. Interaction of four monoterpenes contained in essential oils with model membranes: implications for their antibacterial activity. $J$. Agric. Food Chem. 55:6300-6308.
8. De Bentzmann, S., and P. Plésiat. 2011. The Pseudomonas aeruginosa opportunistic pathogen and human infections. Environ. Microbiol. 13:1655-1665.

9. Desai, M. A., K. A. Soni, R. Nannapaneni, M. W. Schilling, and J. L. Silva. 2012. Reduction of Listeria monocytogenes biofilms on stainless steel and polystyrene surfaces by essential oils. J. Food Prot. 75:1332-1337.

10. European Directorate for the Quality of Medicines \& HealthCare. 2008. Determination of essential oils in herbal drugs, p. 251-252. In European Pharmacopoeia, 6th ed. EDQM Council of Europe, Strasbourg, France.

11. Fasseas, M. K., K. C. Mountzouris, P. A. Tarantilis, M. Polissiou, and G. Zervas. 2007. Antioxidant activity in meat treated with oregano and sage essential oils. Food Chem. 106:1188-1194.

12. Gutierez, J., C. Barry-Ryan, and P. Bourke. 2008. The antimicrobial efficacy of plant essential oil combinations and interactions with food ingredients. Int. J. Food Microbiol. 124:91-97.

13. Hall-Stoodley, L., and P. Stoodley. 2009. Evolving concepts in biofilm infections. Cell Microbiol. 11:1034-1043.

14. Hatew, B., T. Delessa, V. Zakin, and N. Gollop. 2011. Antagonistic intestinal microflora produces antimicrobial substance inhibitory to Pseudomonas species and other spoilage organisms. J. Food Sci. 76: 522-530.

15. Høiby, N., M. Bjarnsholt, M. Givskov, S. Molin, and O. Ciofu. 2010. Antibiotic resistance of bacterial biofilms. Int. J. Antimicrob. Agents 35:322-332.

16. Jaramillo-Colorado, B., J. Olivero-Verbel, E. E. Stashenko, I. Wagner-Dobler, and B. Kunze. 2012. Anti quorum-sensing activity of essential oils from Colombian plants. Nat. Prod. Res. 26:10751086.

17. Kintzios, S. E. 2002. Profile of the multifaceted prince of the herbs, p. 3-8. In S. E. Kintzios (ed.), Oregano: the genera Origanum and Lippia. Taylor \& Francis, London.

18. Kulisic, T., A. Radonic, V. Katalinic, and M. Milos. 2004. Use of different methods for testing antioxidative activity of oregano essential oil. Food Chem. 85:633-640.

19. McLennan, M. W., W. R. Kelly, and D. O'Boyle. 1997. Pseudomonas mastitis in a dairy herd. Aust. Vet. J. 75:790-792.

20. Mishra, B. B., and V. K. Tiwari. 2011. Natural products: an evolving role in future drug discovery. Eur. J. Med. Chem. 46:4769-807.

21. Napoli, E. M., G. Curcuruto, and G. Ruberto. 2009. Screening the essential oil composition of wild Sicilian oregano. Biochem. Syst. Ecol. 37:484-493.

22. Paparella, A., L. Taccogna, I. Aguzzi, C. Chaves-López, A. Serio, F. Marsilio, and G. Suzzi. 2008. Flow cytometric assessment of the antimicrobial activity of essential oils against Listeria monocytogenes. Food Control 19:1174-1182.

23. Rubiolo, R., B. Sgorbini, C. Liberto Cordero, and C. Bicchi. 2010. Essential oils and volatiles: sample preparation and analysis. A review. Flavour Fragr. J. 25:282-290.

24. Schelin, J., N. Wallin-Carlquist, M. T. Cohn, R. Lindqvist, G. C. Barker, and P. Rådström. 2011. The formation of Staphylococcus aureus enterotoxin in food environments and advances in risk assessment. Virulence 2:580-592.

25. Schillaci, D., and M. Vitale. 2012. Biofilm related to animal health, zoonosis and food transmitted diseases: alternative targets for antimicrobial strategy? J. Microbial Biochem. Technol. 4:vii-x.

26. Skoula, M., P. Gotsiou, G. Naxakis, and C. B. Johnson. 1999. A chemosystematic investigation on the mono- and sesquiterpenoids in the genus Origanum (Labiatae). Phytochemistry 52:649-657.

27. Souza, E. L., T. L. M. Stamford, E. O. Lima, and V. N. Trajano. 2005. Effectiveness of Origanum vulgare L. essential oil to inhibit the growth of food spoiling yeasts. Food Control 18:409-413. 